\title{
НАЛОГОВЫЕ ДОХОДЫ БЮДЖЕТОВ ГОРОДСКИХ ОКРУГОВ - СТОЛИЦ ФИННО-УГОРСКИХ АВТОНОМИЙ ПРИВОЛЖСКОГО ФЕДЕРАЛЬНОГО ОКРУГА РФ: АНАЛИЗ И ПРЕДЛОЖЕНИЯ ПО РАСШИРЕНИЮ
}

Аннотация: Финно-угорские автономии Приволжского федерального округа РФ (Республика Мордовия, Марий Эл и Удмуртия), помимо принадлежности к одной языковой общности, характеризуются концентрацией неблагоприятных показателей экономического и демографического развития. Все три региона по размеру среднедушевых доходов, заработной платы и другим социальным показателям населения имеют рейтинг ниже среднего по Российской Федерации и находятся в группе аутсайдеров, как по величине валового регионального продукта, так и по размерам доли бедных в составе населения, по соотношению доходов и заработной платы с прожиточным минимумом. Поскольку именно города - столицы играют ключевую роль в решение вопросов, связанных с региональным развитием, проведем анализ налоговых доходов их бюджетов с челью оценки уровня финансовой обеспеченности и его достаточности для выполнения городом роли "локомотива» развития региона. Поэтому анализ динамики налоговых доходов бюджетов городских округов - столиц финно-угорских автономий Приволжского федерального округа РФ, в настоящее время является довольно актуальным. В результате проведенного анализа было выявлено ряд тенденций в динамике налоговых доходов бюджетов анализируемых городов, а именно:-основным доходным источником в налоговых поступлениях бюджетов всех городских округов является налог на доходы фризических лич;- во всех анализируемых городах налоги на совокупный доход (ЕНВД, ЕСХН, УСН) по объему занимают второе место и их поступления растут;- относительная величины государственной пошлины в структуре налоговых доходов бюджетов г.о. незначительна по сравнению с удельным весом иных федеральных налогов, но вполне сопоставима с поступлениями от местных налогов;- среди местных налогов наибольший удельный вес имеет земельный налог;- минимальную долю в структуре налоговых доходов всех анализируемых городов занимает налог на имущество фризиеских лиц. На основе анализа были предложены и обоснованы меры по укреплению финансово-экономических основ местного самоуправления в Российской Федерации, в частности:- законодательно увеличить не менее чем на 10 процентных пунктов норматив отчислений, зачисляемый в местные бюджеты, от налога на доходы физических лиц;- законодательно закрепить за местными бюджетами долю отчислений по налогу на прибыль в размере не менее 2-3 процентных пунктов;- законодательно закрепить за местными бюджетами норматив отчислений от транспортного налога.Так же были предложены направления развития системы местного налогообложения.

Ключевые слова: Приволжский Федеральный Округ, Муниципальное образование, Городское образование, Бюджет, Налог, Доходная часть бюджета, Налоговые доходы бюджета, Норматив отчисления, Местное налогообложение, Регион.

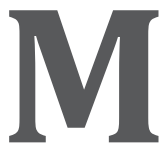
униципальные образования являются самостоятельной целостной системой, привязанной к определенной территории, и базой для решения важнейшей задачи национального масшта- ба - достижения общественно приемлемого уровня качества жизни населения, для решения которой необходима достаточная доходная база. Если полномочия органов местного самоуправления не подкрепле- 
ны соответствующей материально-финансовой базой, то реализация их становится нереальной. В условиях реформы межбюджетных отношений в РФ органы местного самоуправления поставлены в полную зависимость от решений как федеральных, так и региональных органов власти, устанавливающих нормативы отчислений от налогов, дотации и субвенции. Вследствие переноса акцента при формировании доходов бюджетов муниципалитетов с налоговых поступлений на межбюджетные трансферты снизилась связь между располагаемыми финансовыми ресурсами и экономическим развитием соответствующей территории, улучшением условий проживания граждан.

По данным Минфина России, в бюджетах городских округов аккумулируется 63,5 \% (457 миллиардов рублей) налоговых доходов, в бюджетах муниципальных районов - 26,5 \% (190,7 миллиардов рублей) и лишь 10 \% (72,1 миллиарда рублей) - в бюджетах поселений. Таким образом, наибольшая доля налоговых доходов концентрируется в бюджетах крупных промышленно развитых муниципальных образований, которых всего несколько сотен в России. Данные города играют ключевую роль в экономике, именно на их территории в большинстве своем сосредоточены финансовые и товарные рынки, здесь формируются решения, определяющие весь ход экономической жизни региона ${ }^{1}$.

В Приволжском федеральном округе к таковым относятся 6 крупнейших урбанизированных территорий: Казанская, Нижегородская, Самарско-Тольятенская, Пермская, Саратовская, Уфимская агломе-

\footnotetext{
1 Тимченко, В Местное самоуправление: к новым рубежам развития/ В. Тимченко // Муниципальная власть. - 2011. - №5. - С. 9.
}

рации. Экономический рост в округе до 2020 г. будет обеспечен их ускоренным развитием, в том числе за счет миграции населения из субъектов ПФО РФ, не имеющих на своей территории крупных городских агломераций. В группу последних входят финно-угорские автономии Приволжского федерального округа РФ (Республика Мордовия, Марий Эл и Удмуртия), которые помимо принадлежности к одной языковой общности, характеризуются концентрацией неблагоприятных показателей экономического и демографического развития. Все три региона по размеру среднедушевых доходов, заработной платы и другим социальным показателям населения имеют рейтинг ниже среднего по Российской Федерации и находятся в группе аутсайдеров, как по величине валового регионального продукта, так и по размерам доли бедных в составе населения, по соотношению доходов и заработной платы с прожиточным минимумом. Это обусловлено низкими размерами (ниже средних по Поволжью, хотя в Удмуртии эта разница не столь значительна, как в остальных двух республиках) доходов и заработной платы, и высокими темпами естественной и миграционной убыли населения ${ }^{2}$.

Поскольку именно города - столицы играют ключевую роль в решение вопросов, связанных с региональным развитием, проведем анализ налоговых доходов их бюджетов с целью оценки уровня финансовой обеспеченности и его достаточности для выполнения городом роли «локомотива» развития региона.

Сравнение абсолютных величин показателей доходной части бюджетов ис-

\footnotetext{
2 Богатова О. «Финно-угорские» республики Поволжья: территориальные детерминанты социального неравенства / О. Богатова // Казанский федералист. - 2011. №4. - C. 81 .
} 
следуемых городских округов является неуместным по причине ряда различий в количественных показателях их развития, величинах природного и экономического потенциала. Так Ижевск входит в двадцатку крупнейших городов страны, является крупным экономическим, транспортным, торговым и культурным центром страны, известным в стране и мире своими оборонной, машиностроительной и металлургической промышленностью. Йошкар-Ола и Саранск являются аграрно-промышленными, культурными и научными центрами лишь в рамках своих республик. Анализ структуры доходной части бюджетов интересующих нас городских образований позволит сопоставить доли доходов из разных источников (рисунок 1).

Как видно из рисунка 1 наибольшая доля налоговых доходов в бюджете г.о. Ижевск - 51\% (4 536 181,24 тыс. р.). На втором месте - бюджет г.о. Саранск, где данный показатель составил 45\% (2 367 231,6 тыс.р.). И замыкает ряд - г.о. Йошкар-Ола, относительная величина налоговых доходов которого составляет всего 39\% (1 056 938,1 тыс.p.) Лидирующему месту бюджет г.о. Ижевск обязан промышленному производству, доля занятых в котором от среднесписочной численности работников организаций города составляет свыше 32\%. Промышленные предприятия являются основными плательщиками налогов и сборов.

Объективно характеризует уровень бюджетной обеспеченности города и показатель величины налоговых доходов на душу населения (рисунок 2). Как видно из рисунка 2 за 2010-2013 гг. наиболее неблагоприятна динамика налоговых доходов на душу населения в г.о. Йошкар-Ола. Если в 2011 году величина налоговых доходов на душу населения составляла 4389 p., то уже к 2012 году данный показатель снизился на $26 \%$ и составил 3469 р. Однако, уже к 2013 году величина налоговых доходов на душу населения возросла на 478 р. Что касается г.о. Саранск и г.о. Ижевск, то в течение всего рассматриваемого периода наблюдалась тенденция роста данного показателя в обоих городах, при этом величина налоговых доходов на душу населения на начало и конец рассматриваемого периода в г.о. Саранск и Ижевск отличались незначительно. Темп роста налоговых доходов на душу населения в г.о. Саранск за 2010-2012 гг. составил 32,4 \%, который стал максимальным среди рассматриваемых городских округов, превысив аналогичный показатель в г. о. Ижевск на $1,5 \%$.

Рассмотрим состав налоговых доходов бюджетов городов - столиц финно-угорских автономий ПФО.

Анализ приведенных в таблице 1 показателей демонстрирует ряд тенденций в динамике налоговых доходов бюджетов анализируемых городов.

Во-первых, основным доходным источником в налоговых поступлениях бюджетов всех городских округов является налог на доходы физических лиц. Лидером по доле НДФЛ в доходной части в 2013 г. является бюджет г.о. Ижевск (43,9\%), аутсайдером - бюджет г.о. Йошкар-Ола $(28,11 \%)$. При чем, устойчивая тенденция роста абсолютной суммы поступлений по НДФЛ наблюдалась только в г.о. Ижевск и г.о. Саранск. В бюджете г.о. Йошкар-Ола динамика поступления НДФЛ не ровная, с существенным сокращением суммы поступлений в 2012 г., величина которой и в 2013 г. не достигла уровня 2011 г.

Во-вторых, во всех анализируемых городах налоги на совокупный доход (ЕНВД, ЕСХH, УCH) по объему занимают второе 


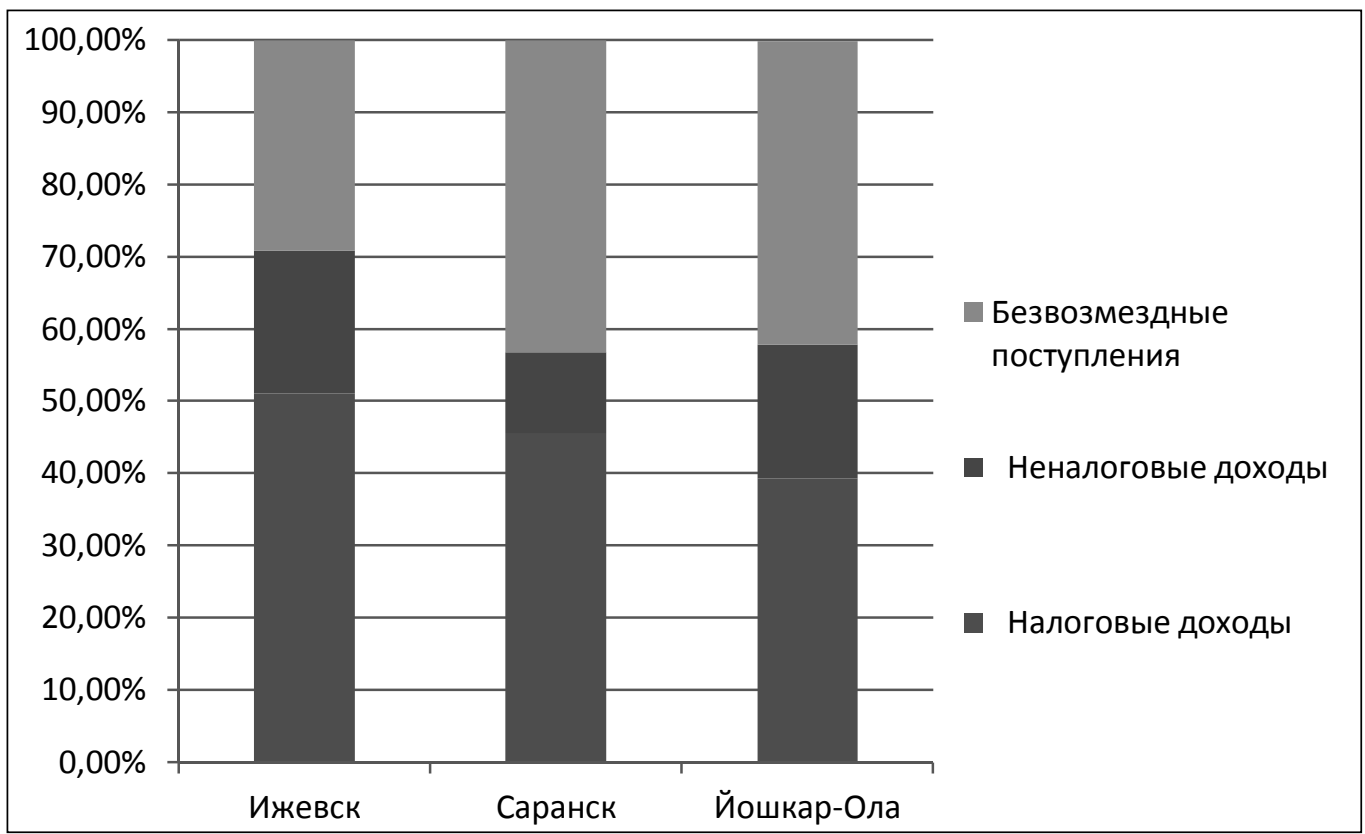

Рисунок 1 - Структура доходной части бюджетов городских округов в 2013 г.

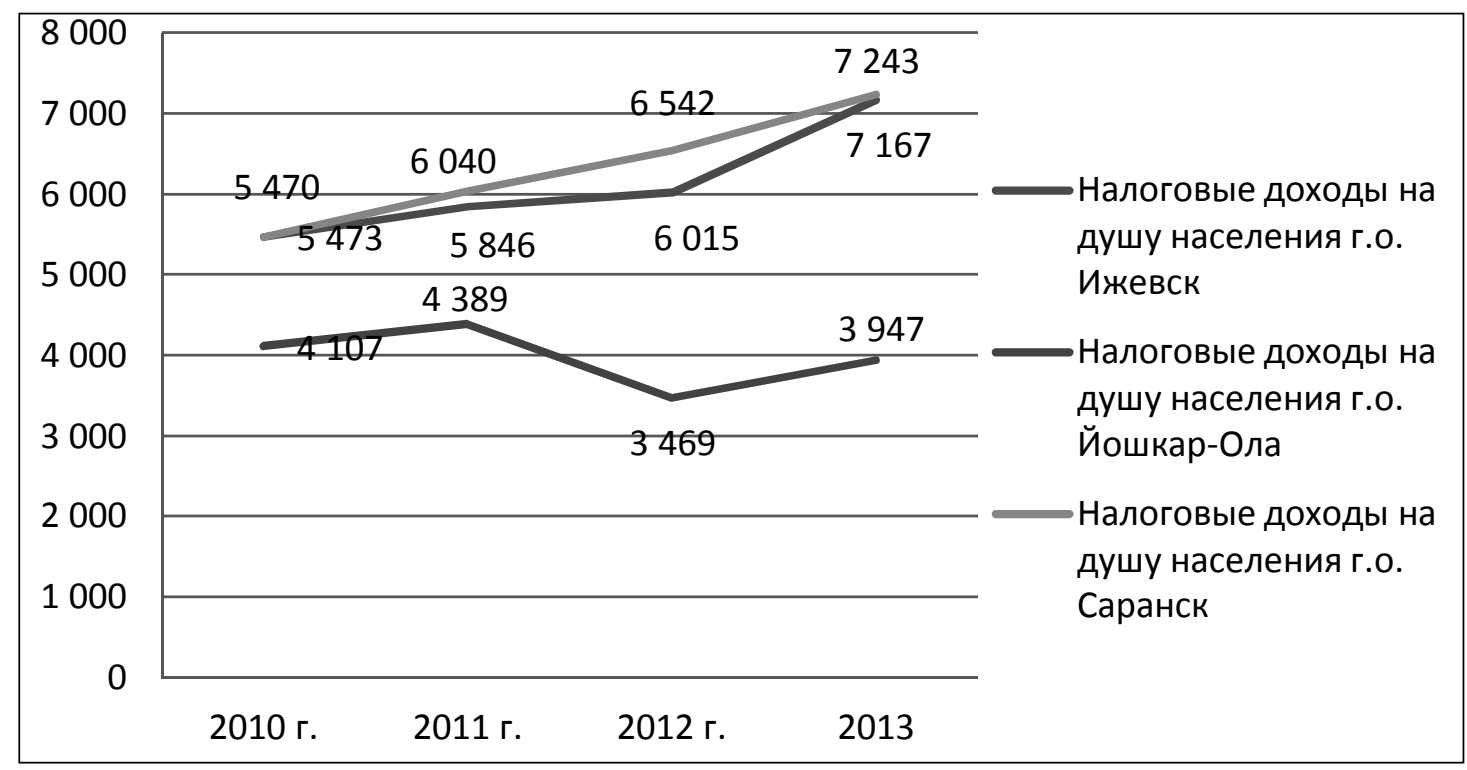

Рисунок 2 - Динамика показателей налоговых доходов на душу населения в городских округах, p.

место и их поступления растут. Это свидетельствует, прежде всего, о развитии на территории городов малого и среднего бизнеса. По абсолютным значениям поступлений лидируют г.о. Ижевск и г.о. Саранск, но их доля в налоговых доходах бюджета самая высокая в г.о. Йошкар-Ола. При чем, в бюджет г.о. Ижевск отчисления от ЕСХН не поступают, чем и объясняется его отставание по доли поступления налогов на совокупный доход от аналогичного показателя по г.о. Саранск.

В-третьих, относительная величины государственной пошлины в структуре налоговых доходов бюджетов г.о. незначительна по сравнению с удельным 


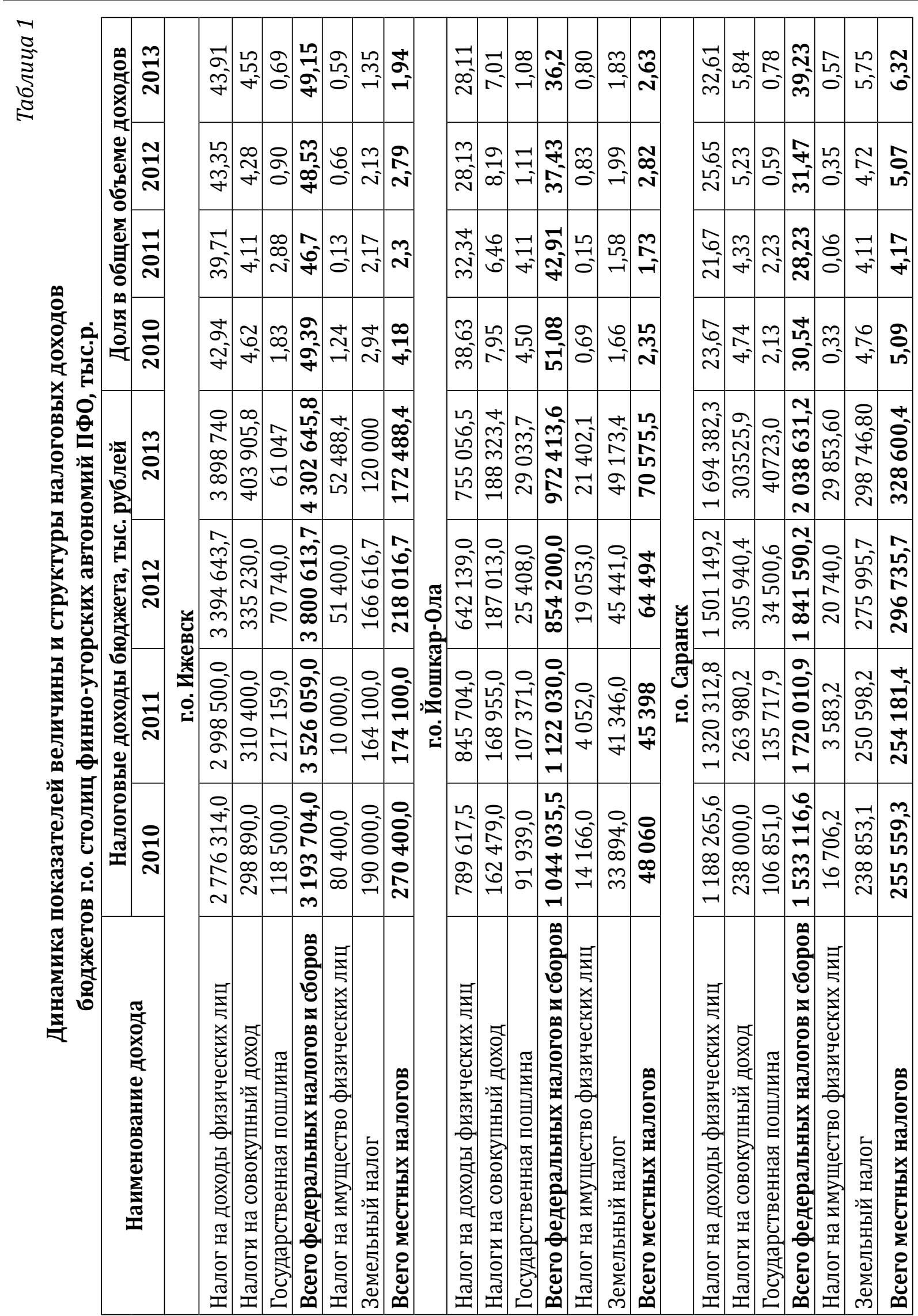


весом иных федеральных налогов, но вполне сопоставима с поступлениями от местных налогов. За весь период анализа прослеживается устойчивая тенденция сокращения поступлений как в абсолютной сумме, так и в процентах от итоговых величин. Так в 2012 г. по сравнению с 2011 г. снизились поступления государственной пошлины в бюджеты г.о. Саранск практически на 75\%, г.о. Ижевск - на 67\%, г.о. Йошкар-Ола - на $76 \%$. Основная причина - изменения, внесенные в Бюджетный кодекс Российской Федерации, в соответствии с которыми госпошлина за регистрацию транспортных средств с 1 января 2012 года перестала являться источником доходов местных бюджетов.

В-четвертых, среди местных налогов наибольший удельный вес имеет земельный налог. Какпо абсолютным его поступлениям, так и по доле в общей сумме налоговых доходов лидирует бюджет г.о. Саранск, что является следствием, прежде всего, качественно проведенных работ по актуализации кадастровой стоимости и уточнению правообладателей более 10 тысяч земельных участков. В г.о. Саранск темп роста поступлений по земельному налогу составил 110\%, в г.о. Йошкар-Ола - 109\%.Причиной роста поступлений платежей от налогоплательщиков - физических лиц по земельному налогу, стало также повышение ставок налога. Противоположная тенденция установилась в г.о. Ижевск, где поступления по земельному налогу за 2010-2013 гг. снизились на 70000 тыс.р., таким образом, темп убыли составил 158\%. Данное сокращение связано со снижением средневзвешенного удельного показателя кадастровой стоимости земель за весь период более чем в 2 раза.

B-пятых, минимальную долю в структуре налоговых доходов всех анализируемых городов занимает налог на имущество физических лиц. Динамика изменения поступлений неоднозначна: рост в 2012 году (от 4,7 раза в Йошкар-Оле, до 5,1 раза в Ижевске и 5,7 раза в Саранске), снижение в предыдущие периоды. Причина в банальном изменении срока уплаты налоговых платежей (внесение изменений в закон РФ от 09.12.1991 № 2003-1 «0 налогах на имущество физических лиц»). С 01 января 2011 года налог на имущество физических лиц уплачивается не позднее 01 ноября года, следующего за годом его исчисления. При этом роль налогового источника осталась неизменно малой.

Таким образом, в совокупности поступления от местных налогов составляют несколько процентов от налоговых доходов бюджетов городских округов (не более $1 \%$ от налога на имущество физических лиц и 1,3-5,7 \% от земельного налога). Местные налоги не обеспечивают должную финансовую основу деятельности администраций городских образований. Причины, прежде всего, общие для всех муниципалитетов: право собственности граждан зачастую не оформлено надлежащим образом; большое количество незавершенного строительства; недостаточное внимание налоговых органов к сбору местных налогов изза невозможности доначислить крупные суммы и др. Однако, для бюджетов малых городов основным фактором, ограничивающим поступления как по НДФЛ, так и по местным налогам являются низкие доходы населения, не позволяющие им существенно улучшить свое имущественное положение. Для сравнения в бюджете городских округов со средней заработной платой, примерно в 2 раза превышающей аналогичный показатель в анализируемых городах финно-угорской группы, выше и доля местных налогов в общей их величине. Так 
по плану в 2013 г. в бюджете г.о. Казань она составляла 28,7 \%, в г.о. Пермь - 23,1 \%, г.о. Самара - 20,4 \%. Поэтому существующая уже сейчас зависимость - чем меньше городской округ, тем меньшую долю в его бюджете занимают местные налоги - будет со временем только увеличиваться.

Основная часть налоговых доходов городских округов, как показал проведенный анализ, формируется за счет отчислений от федеральных налогов и сборов, а также от налогов на совокупный доход, на регулирование порядка взимания которых органы местного самоуправления не могут оказывать какого либо значительного влияния ${ }^{3}$. От региональных налогов в бюджеты городских округов финно-угорской группы отчисления не установлены.

Для укрепления финансово-экономических основ местного самоуправления в Российской Федерации в научной литературе на протяжении нескольких лет обсуждается необходимость и возможность увеличения нормативов отчислений от федеральных и региональных налогов с некоторыми различиями в величине процентов:

- законодательно увеличить не менее чем на 10 процентных пунктов норматив отчислений, зачисляемый в местные бюджеты, от налога на доходы физических лиц;

- $\quad$ законодательно закрепить за местными бюджетами долю отчислений по налогу на прибыль в размере не менее 2-3 процентных пунктов;

- законодательно закрепить за местными бюджетами норматив отчислений от транспортного налога.

\footnotetext{
3 Тимченко, В Местное самоуправление: к новым рубежам развития/ В. Тимченко // Муниципальная власть. 2011. — №5. - C. 9.
}

610
Безусловно, для городских округов столиц регионов с отстающим уровнем социально-экономического развития - это необходимая мера. Рост налоговых доходов, пусть даже не собственных, существенно укрепит их финансовую самостоятельность и расширит возможности по стимулированию развития на своей территории бизнеса, как малого, так и крупного, который будет, в свою очередь способствовать росту заработных плат. Однако, на практике федеральным центром проводится иная политика. Так с 01.01.2014 г. в очередной раз норматив отчислений от налога на доходы физических лиц был увеличен в региональный бюджет и сокращен в местный. Ограниченные объемом статьи, мы не будем долго останавливаться на оценке рациональности действующего или предлагаемых в научной литературе пропорций раздела «федерального налогового пирога». Прежде всего, региональные органы власти, по нашему мнению, должны осознать необходимость закрепления за своей столицей роли «локомотива» развития всего региона и предоставить им большую долю отчислений от налогов, поступающих в региональный бюджет.

Сделаем акцент и на том, что для малых городских округов (не столиц) и поселений, тем более сельских поселений, величина норматива отчислений не играет особой роли по причине малых налоговых баз по налогам на доходы (прибыль) и имущество соответственно физических и юридических лиц на их территориях. И до тех пор пока величина дотаций местным бюджетам сокращается при увеличении их налоговых доходов, ситуация не изменится. Местные администрации не заинтересованы в привлечении на свои территории налогоплательщиков, ведь общая сумма доходов бюджета при этом существенно не изменится. 
В части развития системы местного налогообложения остаются актуальными следующие направления:

- ускорить работы по введению единого налога на недвижимость;

- предусмотреть компенсацию местным бюджетам потерь, вызванных федеральными актами об освобождении от уплаты местных налогов крупных объектов федерального значения, либо отменить соответствующие статьи Налогового кодекса Российской Федерации 4 . Среди предложений организационного характера наиболее результативным может стать расширение участия органов местного самоуправления и органов государственной власти субъектов Российской Федерации в администрировании поступающих в их бюджеты местных, региональных и даже федеральных налогов. Увеличить собираемость налогов силами только налоговых органов в условиях роста числа налогоплательщиков и сокращения численности налоговых инспекторов даже при условии повышения уровня информатизации процесса налогового администрирования - задача не реальная. Межрайонные налого- вые инспекции существенно удалены от налогоплательщиков и не могут знать особенности их финансово-хозяйственной деятельности лучше представителей местных администраций.

И в заключении, отметим, что в условиях законодательно одобренной стратегии пространственного развития ПФО РФ за счет зон опережающего развития, в число которых финно-угорские автономии округа не попали, единственно правильным решением видится объединение их усилий в вопросах стимулирования экономического роста и предотвращения оттока ресурсов, в том числе трудовых. К примеру, проведение единых программ по развитию национального туризма (туристических маршрутов, масштабных культурно-массовых мероприятий) на территории сразу трех регионов вполне может стать основой формирования новых налоговых баз. Разработка и реализация согласованных региональных налоговых политик будет способствовать формированию равных налоговых условий на их территориях с целью привлечения крупных и стимулирования роста малых налогоплательщиков.

\section{Библиография:}

1. Богатова 0. «Финно-угорские» республики Поволжья: территориальные детерминанты социального неравенства / О. Богатова // Казанский федералист. - 2011. №4. - С. 77-103.

2. Перцов Л. Анализ финансового состояния муниципальных образований и предложения по укреплению доходной базы местных бюджетов / Л. Перцов //Муниципальная власть. - 2012. — №1. - С. 51-55.

3. Тимченко, В Местное самоуправление: к новым рубежам развития/ В. Тимченко // Муниципальная власть. - 2011. - №5. - С. 8-15.

\footnotetext{
4 Перцов Л. Анализ финансового состояния муниципальных образований и предложения по укреплению доходной базы местных бюджетов / Л. Перцов // Муниципальная власть. - 2012. — №1. - С.55.
} 
4. Отчет об исполнении бюджета городского округа «Город Йошкар-Ола» за 2010 год. [Электронный ресурс] // (сайт информационно-правовой компании Гарант). - Peжим доступа: http://base.garant.ru/

5. Отчет об исполнении бюджета городского округа «Город Йошкар-Ола» за 2011 год. [Электронный ресурс] // (сайт информационно-правовой компании Гарант). - Peжим доступа: http://base.garant.ru/

6. Отчет об исполнении бюджета городского округа «Город Йошкар-Ола» за 2012 год. [Электронный ресурс] // (сайт информационно-правовой компании Гарант). - Peжим доступа: http://base.garant.ru/

7. Отчет об исполнении бюджета городского округа «Город Йошкар-Ола» за 2013 год. [Электронный ресурс] // (сайт информационно-правовой компании Гарант). - Peжим доступа: http://base.garant.ru/

8. Отчет об исполнении бюджета городского округа Саранск за 2010 год. [Электронный ресурс] // (сайт информационно-правовой компании Гарант). - Режим доступа: http://base.garant.ru/

9. Отчет об исполнении бюджета городского округа Саранск за 2011 год.[Электронный pecypc] // (сайт информационно-правовой компании Гарант). - Режим доступа: http://base.garant.ru/

10. Отчет об исполнении бюджета городского округа Саранск за 2012 год[Электронный pecypc] // (сайт информационно-правовой компании Гарант). - Режим доступа: http://base.garant.ru/

11. Отчет об исполнении бюджета городского округа Саранск за 2013 год.[Электронный pecypc] // (сайт информационно-правовой компании Гарант). - Режим доступа: http://base.garant.ru/

12. Отчета об исполнении бюджета муниципального образования «Город Ижевск» за 2010 г. [Электронный ресурс] // (сайт информационно-правовой компании Гарант). - Режим доступа: http://base.garant.ru/

13. Отчета об исполнении бюджета муниципального образования «Город Ижевск» за 2011 г. [Электронный ресурс] // (сайт информационно-правовой компании Гарант). - Режим доступа: http://base.garant.ru/

14. Отчета об исполнении бюджета муниципального образования «Город Ижевск» за 2012 г. [Электронный ресурс] // (сайт информационно-правовой компании Гарант). - Режим доступа: http://base.garant.ru/

15. Отчета об исполнении бюджета муниципального образования «Город Ижевск» за 2013 г. [Электронный ресурс] // (сайт информационно-правовой компании Гарант). - Режим доступа: http://base.garant.ru/

\section{References:}

1. Bogatova O. «Finno-ugorskie» respubliki Povolzh'ya: territorial'nye determinanty sotsial'nogo neravenstva / O. Bogatova // Kazanskii federalist. - 2011.-№4. - S. 77-103.

2. Pertsov L. Analiz finansovogo sostoyaniya munitsipal'nykh obrazovanii i predlozheniya po ukrepleniyu dokhodnoi bazy mestnykh byudzhetov / L. Pertsov //Munitsipal'naya vlast'. 2012. — №1. - S. 51-55. 
3. Timchenko, V Mestnoe samoupravlenie: k novym rubezham razvitiya/ V. Timchenko // Munitsipal'naya vlast'. — 2011. — №5. - S. 8-15.

4. Otchet ob ispolnenii byudzheta gorodskogo okruga «Gorod Ioshkar-Ola» za 2010 god. [Elektronnyi resurs] // (sait informatsionno-pravovoi kompanii Garant). — Rezhim dostupa: http://base.garant.ru/

5. Otchet ob ispolnenii byudzheta gorodskogo okruga «Gorod Ioshkar-Ola» za 2011 god. [Elektronnyi resurs] // (sait informatsionno-pravovoi kompanii Garant). — Rezhim dostupa: http://base.garant.ru/

6. Otchet ob ispolnenii byudzheta gorodskogo okruga «Gorod Ioshkar-Ola» za 2012 god. [Elektronnyi resurs] // (sait informatsionno-pravovoi kompanii Garant). - Rezhim dostupa: http://base.garant.ru/

7. Otchet ob ispolnenii byudzheta gorodskogo okruga «Gorod Ioshkar-Ola» za 2013 god. [Elektronnyi resurs] // (sait informatsionno-pravovoi kompanii Garant). — Rezhim dostupa: http://base.garant.ru/

8. Otchet ob ispolnenii byudzheta gorodskogo okruga Saransk za 2010 god. [Elektronnyi resurs] // (sait informatsionno-pravovoi kompanii Garant). - Rezhim dostupa: http:// base.garant.ru/

9. Otchet ob ispolnenii byudzheta gorodskogo okruga Saransk za 2011 god.[Elektronnyi resurs] // (sait informatsionno-pravovoi kompanii Garant). - Rezhim dostupa: http://base.garant. $\mathrm{ru} /$

10. Otchet ob ispolnenii byudzheta gorodskogo okruga Saransk za 2012 god[Elektronnyi resurs] // (sait informatsionno-pravovoi kompanii Garant). — Rezhim dostupa: http://base.garant. $\mathrm{ru} /$

11. Otchet ob ispolnenii byudzheta gorodskogo okruga Saransk za 2013 god.[Elektronnyi resurs] // (sait informatsionno-pravovoi kompanii Garant). — Rezhim dostupa: http://base.garant. $\mathrm{ru} /$

12. Otcheta ob ispolnenii byudzheta munitsipal'nogo obrazovaniya «Gorod Izhevsk» za $2010 \mathrm{~g}$. [Elektronnyi resurs] // (sait informatsionno-pravovoi kompanii Garant). — Rezhim dostupa: http://base.garant.ru/

13. Otcheta ob ispolnenii byudzheta munitsipal'nogo obrazovaniya «Gorod Izhevsk» za $2011 \mathrm{~g}$. [Elektronnyi resurs] // (sait informatsionno-pravovoi kompanii Garant). — Rezhim dostupa: http://base.garant.ru/

14. Otcheta ob ispolnenii byudzheta munitsipal'nogo obrazovaniya «Gorod Izhevsk» za $2012 \mathrm{~g}$. [Elektronnyi resurs] // (sait informatsionno-pravovoi kompanii Garant). — Rezhim dostupa: http://base.garant.ru/

15. Otcheta ob ispolnenii byudzheta munitsipal'nogo obrazovaniya «Gorod Izhevsk» za $2013 \mathrm{~g}$. [Elektronnyi resurs] // (sait informatsionno-pravovoi kompanii Garant). — Rezhim dostupa: http://base.garant.ru/ 